\title{
Smart System: IOT for voice enabled Gas Pumps at Petrol Pumps
}

\author{
Shobhit Mangla ${ }^{1}$, Animesh Singh ${ }^{2}$, Dr. Kamlesh Sharma ${ }^{3}$ \\ \{1 shobhitmangla011@gmail.com, ${ }^{2}$ singhanimesh.9643@gmail.com, ${ }^{3}$ kamlesh.fet@mriu.edu.in, \\ kamlesh0581@gmail.com \}
}

CSE, FET, Manav Rachna International Institute of Research \& Studies Faridabad,India

\begin{abstract}
IOT, it results in an immensely dependable technology that can be implemented in daily life to amplify their efficiency and reliability. For a pragmatic The world have entered an era where the IOT i.e. Internet of Things is being implemented in smart technologies to provide help with labor and make various tasks easier. Internet of Things is a network comprising of smart machines which communicate with other machines, objects and the environment. It is a great challenge to develop a general architecture of IOT due to complexity of the link layer technologies and real time analytic capabilities. Natural Language processing -evolved version of Air Pump technology that is found at Gas Stations where, the customer would simply speak the desired tyre size into the mic and the requisite air usage, this paper has been made to focus on developing a system that is combined with both, IOT and Voice Recognition technology. The purpose of this system is to provide a much input will be calculated by the machine and displayed on the panel. The attendant would simply need to fill the air, making the process fast and simple.
\end{abstract}

Keywords: Internet of Things, Natural Language Processing, Air Pump Technology, Development, Voice Recognition, Smart Cities, IOT(Internet of Things).

\section{Introduction}

Internet of Things or IOT is a concept of connecting physical devices over network connectivity and enabling a communication to occur between internet-enabled devices and systems. IoT has enabled traditional devices like laptops, desktop computers, smartphones to have an internet connectivity and communication between the new tech gadgets. IOT devices are smart enough to know, observe, identify, and understand the surrounding situation without depending on humans. It uses sensors to communicate over the internet. IOT technology is based on big data management tools, AI, machine learning nd predictive analytic tools.[1]

As shown in Fig 1,now a days, IOT is widely spread among different fields.It is being applied in wearables, smart homes and building, vehicles, manufacturing,supplyhains,agriculture,healthcare and energy.

Therefore, IOT is an essential technology that is required to be implemented to help in the development of smart cities. India is currently working on the goal, to make a hundred cities smart i.e, make them easy enough for civilians to use and sustainable. The proposed system 
helps by playing a minor but really important role in this development since it's main goal is to save time and reduce the labour that is currently being exhausted.[2]

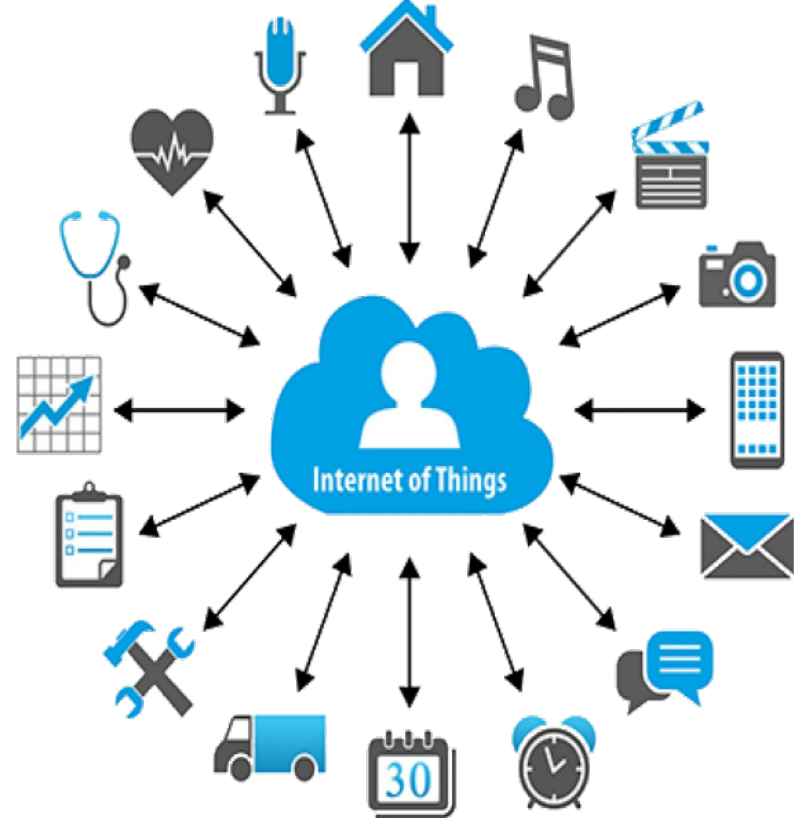

Fig 1: Areas where IOT can be implemented to help in the development of smart cities[3].

\section{Working of IOT}

IOT is based on four different components to generate a result. These are, sensors, connectivity, data processing and user interfaces.

Sensors: Sensors are those devices which sense the surrounding to collect information. There are different types of sensors like heat sensors, temperature sensors, light sensors, voice recognition, accelerometer and many more. These sensors collect the specific type of information they are programmed to.

Connectivity: In the next step, the sensor has to send the collected information to the cloud through a connection. The connectivity between the data sending device and the cloud can be achieved through the wifi, Bluetooth, low power wide area networks, cellular networks, satellites or having a wired connection.

Data processing: The data at the cloud isprocessed to give a result to the user. Here the data received from sensor is interpreted to give an accurate result.For example, light sensorsdetect the presence of light, the temperature sensor detects the temperature, the voice recognition detects the type of voice and what the user is trying to say. 
User interface:The result is generated in a human understandable form and the user is notified by an alert message or mail or, he can check his mobile phone through a specified app the device[4]

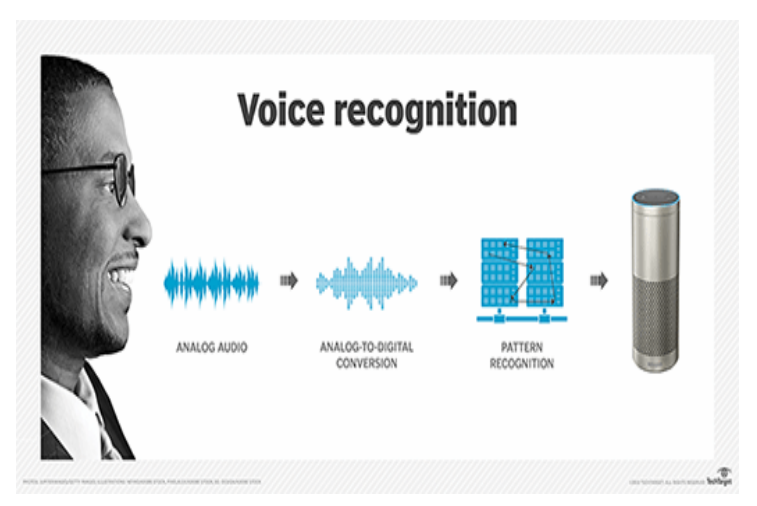

Fig 2: The basic model of voice Recognition[5].

As shown in the Fig 2, voice recognition is a program that works by analyzing the sound to perform the specific task based on the information provided. In today's world, every new gadget has voice recognition program just like Apple's SIRI is used to search, reminding just by speaking and doing web search.

Google is just another Siri for android phones, Google Home is a speaker that play the song which the user wants by reading out the name, Amazon's Alexa is latest gadget that has been manufactured and codedfor users to play the songs according to their mood and choices.

Voice recognition works by linking natural language processing to speech recognition. Acoustic and linguistic modeling algorithm are mainly used in speech recognition programs. The connection between linguistic units of language of modeling, speech and audio signifies an acoustic modeling. Both these technologies can be used in homes and various other places which enables users to speak to their own device and helps with the conversion of their voice into a text form.[6]

\section{Literature Review}

Zeinab Namak Aldein Mohamned research makes the world aware with the Internet Of Things. The paper discussed about different applications of IOT and implementations of IOT applications to make the world smart. The IOT enabled system helps to make the smart cities, smart environment, smart energy, smart manufacturing and smart healthcare. [7]

Om Prakash Prabhakar, Navneet Kumar Sahu research is mainly done to improve the human voice recognition system. In this paper it presents the recognition performance of numeric digits and speech alphabets by the help of Gaussian mixture model, the paper proposed the method which able to recognized digits from zero to nine and A to Z.[8] 
The authors Joshua E. Siege, Sumeet Kumar, Sanjay E. Sarma have focused on working over the idea of improving security through "remote data fusion". In this paper, concepts like data proxy and cognitive layer have been considered and explained briefly. Work has been done upon practical models by implementing IOT to reduce the energy used by processes in the cloud and therefore reducing cost in a really effective manner[9].

The authors Andrea Zanella, Nicola Bui, Angelo Castellani, Lorenzo Vangelista, Michele Zorzi have discussed about implementation of IOT in technologies in urban areas can result in a well developed smart city by taking the example of the Padova Smart City in Italy. The main vision is to develop most advanced communicationtechnologies to provide support to the citizens.

The authors Sapna Suryawanshi, Rohini Bhuse, MeghaGite , Dhanashri Hande discussed an idea for a smart waste management system . Here they are using led, ultrasonic sensor, buzzer alarm and an arduino board. Using these the authors are trying to make a bin smarter . whenever the dustbin cross the threshold level the alarm buzzer makes a sound and a message is sent to the concerned authority so that it can be clean as soon as possible.[10].

The authors Prof.J.N.Nandimath,VarshaAlekar, Sayali Joshi, Sonal Bhite, Pradnya Chaudhari talked about the fuel monitoring system in future vehicles as the fuel filled and fuel consumption is not accurately shown. To avoid this problem, implementation of an IOT fuel monitoring and tracking system is introduced. Using different sensors the system tried to resolve the problem and all the data of fuel filled is saved on cloud and application itself.[11]

The author K.Sharma, discussed an IoT (Internet of things) based system for the University campus. The system analyzes the usage of all electrical and electronic devices and optimizes the power consumption. The system is developed using a combination of IoT, Wireless Sensors, Network Security, Green IT, Big Data Analysis. Special IoT sensors is installed with every Electrical and Electronic device which sends the data to the cloud. The Whole network is monitored by computer expert system which immediately notifies the operation and maintenance team to take appropriate action on time. Using BIG data analysis, it optimizes the usage of all device and power consumption. It helps to improve the response time of operation and cost by the maintenance team.[12]

To increasing system simplicity and flexibility, an audio evoked based system was developed by integrating simplified headphone and user-friendly software design. This paper describes a Hindi Speech Actuated Computer Interface for Web search (HSACIWS), which accepts spoken queries in Hindi language and provides the search result on the screen. This system recognizes spoken queries by large vocabulary continuous speech recognition (LVCSR), retrieves relevant document by text retrieval, and provides the search result on the Web by the integration of the Web and the voice systems.

\section{System Design}

The system is designed by integrating the IOT sensors (e.g Zigbee Sensors and Gateway) with every electrical and electronic device, the sensors[15][16] will sense and communicate with smart network [12] as shown in figure 3. The smart Network system interconnects all sensors as shown in figure 3 . The proposed system is a centralized monitoring with auto notification 
feature, with the help of big data analysis, optimization of the usage of all devices and power was possible. The command is recognized by the system and accordingly the press of air is set for tyres.[13][14]

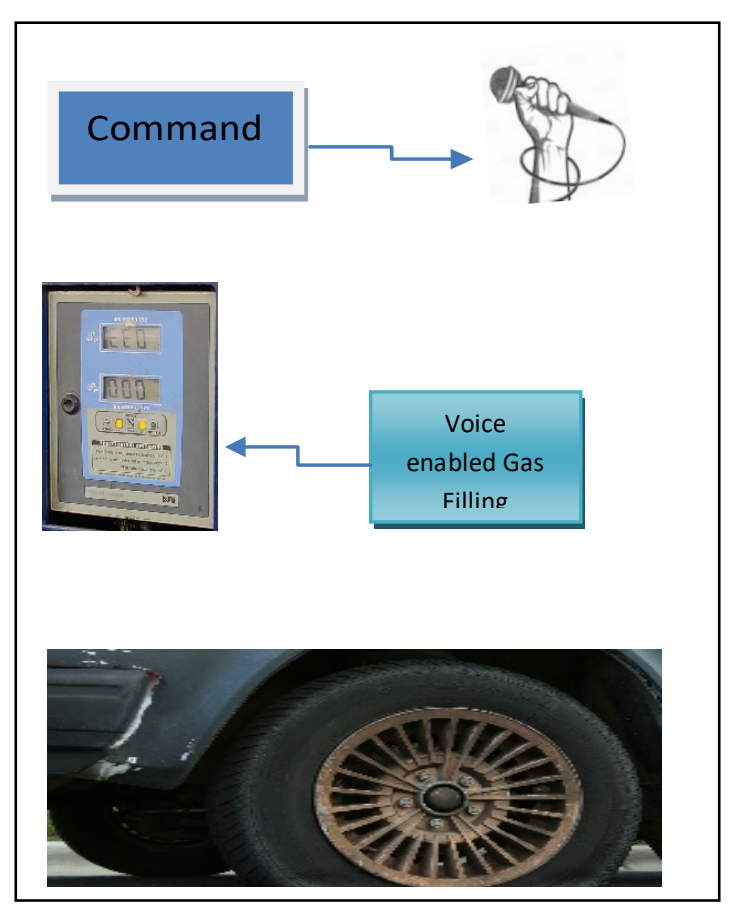

Fig 3: System Design of Voice enable air pump system [self]

\section{Methodology}

The current existing system on the petrol in Indian is manual. The users set the pressure manually with hands and then fill the gas in vehicles as shown in fig. 4 .

The available systems do not support automatic pressure check mechanism to check the current pressure in the tyre. The machine takes the input in the form of pressing a button on machine.

The System starts by pressing the button located near the nozzle and takes voice commands, can be in English or Hindi from the user. 


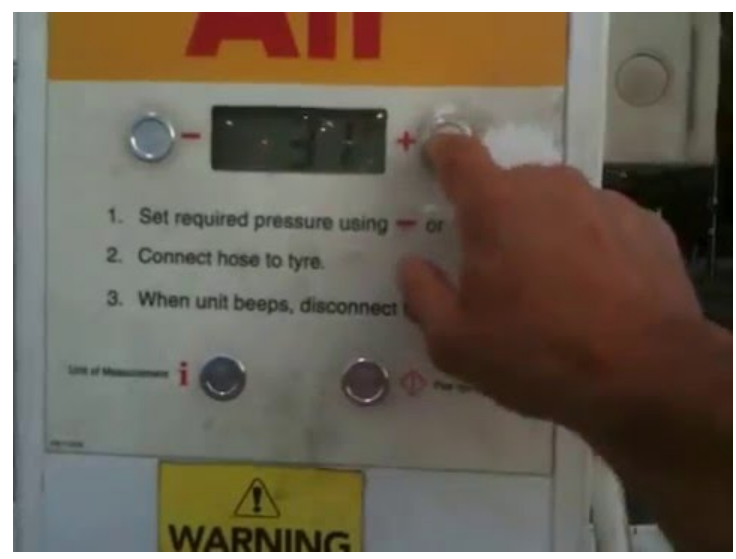

Fig 4: The current air pump system [self]

The recognized command is used to set the gas pressure for tyre. The developed module check

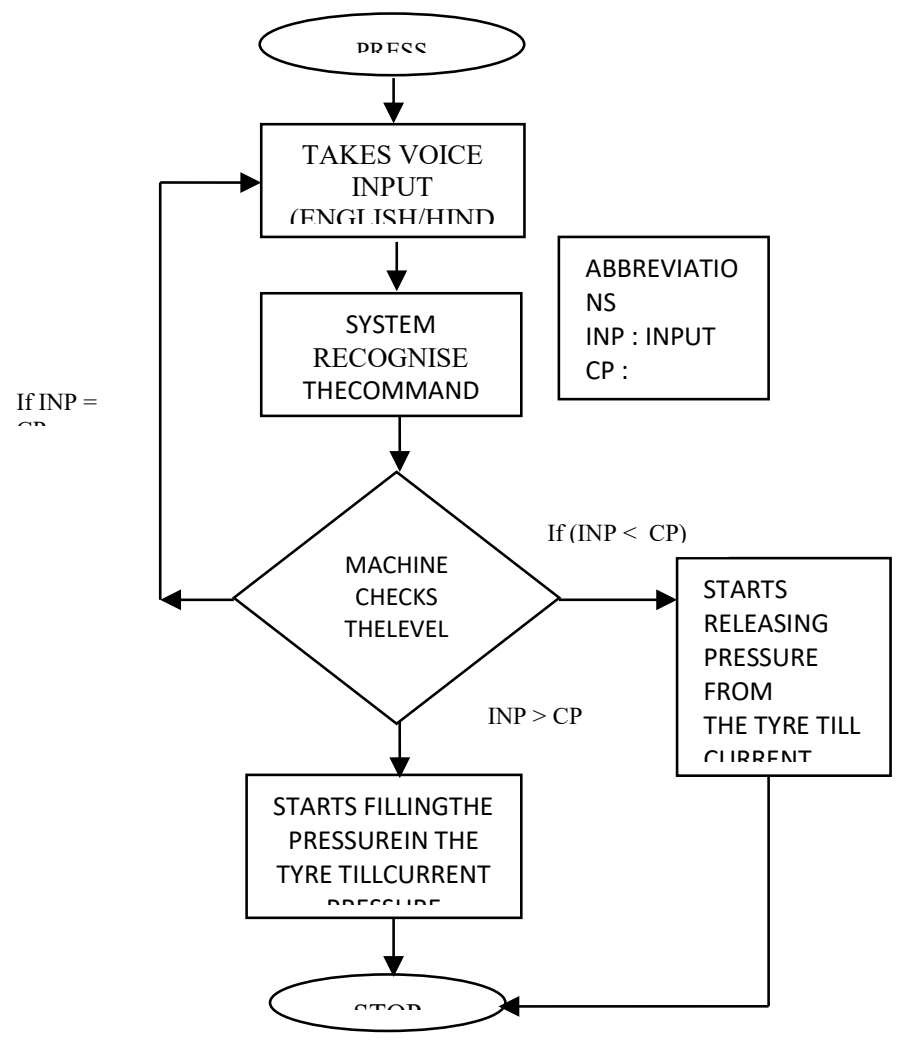

Fig 5: Flow chart of working model of voice enable air pump system 
the current pressure of tyre with the pressure set by the user. If the input gas pressure is greater than the gas pressure present in the tyre then the gas is pumped into the tyre. If the input gas pressure is less than the pressure present in the tyre then the gas is released from the tyre till the set pressure and if the initial pressure and the input pressure are equal the whole process will be repeat again for the next input as shown in fig 5 .

\section{Result and Discussion}

The current scenario of Indian fuel pumps is that they require a large amount of man power. The system is not in support to reduce the man power at fuel pumps but just want to make their work more efficient by implementing a small idea of IOT into it.

The Internet of Things has reached the self-service fuel centre and is changing the way customers pump their gas and the way operators monitor their tanks. Many gas station's underground tanks are a hodgepodge of new and old technologies, often requiring attendants to manually measure their tanks for overfilling, leaks, and other concerns.

Table 1: Survey Data from different Petrol Pumps for gas filling

\begin{tabular}{|c|c|c|c|c|c|}
\hline S.No & $\begin{array}{l}\text { Name of } \\
\text { Petrol } \\
\text { Pump }\end{array}$ & Location & $\begin{array}{l}\text { No. } \\
\text { of } \\
\text { air } \\
\text { pum } \\
\text { ps }\end{array}$ & $\begin{array}{l}\text { Four } \\
\text { wheelers }\end{array}$ & $\begin{array}{l}\text { Time } \\
\text { taken } \\
\text { to fill } \\
\text { air }\end{array}$ \\
\hline 1 & $\begin{array}{l}\text { Bharat } \\
\text { Petrolium }\end{array}$ & $\begin{array}{l}\text { Suraj } \\
\text { kundFaridaba } \\
\text { d }\end{array}$ & 2 & Swift & $\begin{array}{l}1 \mathrm{~min} \\
37 \mathrm{sec}\end{array}$ \\
\hline 2 & $\begin{array}{l}\text { Hindustan } \\
\text { Petrolium }\end{array}$ & Jasola Delhi & 2 & Scorpio & $\begin{array}{l}2 \mathrm{~min} \\
50 \mathrm{sec}\end{array}$ \\
\hline 3 & Indian Oil & VashaliGzb & 1 & Eon & $\begin{array}{l}1 \mathrm{~min} \\
52 \mathrm{sec}\end{array}$ \\
\hline 4 & Indian Oil & $\begin{array}{l}\text { IndrapuramGa } \\
\text { ziyabad }\end{array}$ & 1 & Brio & $\begin{array}{l}1 \mathrm{~min} \\
48 \mathrm{sec}\end{array}$ \\
\hline 5 & Indian Oil & Jasola Delhi & 1 & $\begin{array}{l}\text { Swift } \\
\text { Dezir }\end{array}$ & $\begin{array}{l}2 \mathrm{~min} \\
36 \mathrm{sec}\end{array}$ \\
\hline 6 & $\begin{array}{l}\text { Hindustan } \\
\text { Petrolium }\end{array}$ & $\begin{array}{l}\text { Vasundhara } \\
\text { Ghaziabad }\end{array}$ & 1 & $\begin{array}{l}\text { Zen } \\
\text { Estelio }\end{array}$ & $\begin{array}{l}1 \mathrm{~min} \\
11 \mathrm{sec}\end{array}$ \\
\hline 7 & $\begin{array}{l}\text { Hindustan } \\
\text { Petrolium }\end{array}$ & $\begin{array}{l}\text { Asharam } \\
\text { Delhi }\end{array}$ & 2 & $\begin{array}{l}\text { Nisan } \\
\text { Micra }\end{array}$ & $\begin{array}{l}1 \mathrm{~min} \\
03 \mathrm{sec}\end{array}$ \\
\hline 8 & Indrapratha & $\begin{array}{l}\text { Pehladpur } \\
\text { Delhi }\end{array}$ & 1 & Santro & $\begin{array}{l}1 \mathrm{~min} \\
48 \mathrm{sec}\end{array}$ \\
\hline 9 & $\begin{array}{l}\text { Hindustan } \\
\text { Petrolium }\end{array}$ & $\begin{array}{l}\text { Sahibabad } \\
\text { Ghaziabad }\end{array}$ & 1 & Fortuner & $\begin{array}{l}2 \mathrm{~min} \\
32 \mathrm{sec}\end{array}$ \\
\hline 10 & $\begin{array}{l}\text { Hindustan } \\
\text { Petrolium }\end{array}$ & $\begin{array}{l}\text { Kalandi Kunj } \\
\text { Delhi }\end{array}$ & 1 & $\begin{array}{l}\text { Inova } \\
\text { Crysta }\end{array}$ & $\begin{array}{l}3 \mathrm{~min} \\
02 \mathrm{sec}\end{array}$ \\
\hline
\end{tabular}

The table 1 data is converted in table 2 to analysis the time parameter and measures the time taken by different vehicles in terms of seconds. 
Table 2: Time taken by vehicle to fill gas in terms of seconds

\begin{tabular}{|l|l|l|}
\hline S.No & Vehicle Type & $\begin{array}{l}\text { Time taken to fill gas (in } \\
\text { Seconds) }\end{array}$ \\
\hline 1 & Swift & 97 \\
\hline 2 & Scorpio & 170 \\
\hline 3 & Eon & 112 \\
\hline 4 & Brio & 108 \\
\hline 5 & Swift Dezir & 156 \\
\hline 6 & Zen Estelio & 71 \\
\hline 7 & Nisan Micra & 63 \\
\hline 8 & Santro & 108 \\
\hline 9 & Fortuner & 152 \\
\hline 10 & Inova Crysta & 182 \\
\hline Average Time taken & 121.9 \\
\hline
\end{tabular}

The graphical representation of the table 2 is represented in graph 1 and graph 2 .

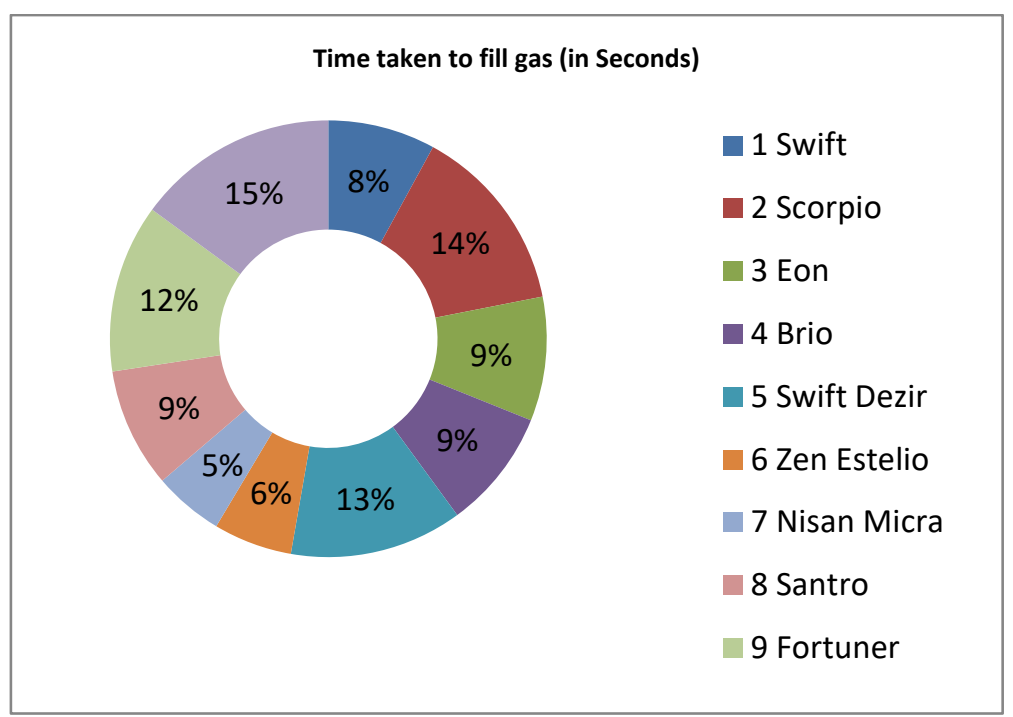

Graph 1:Time(in sec) taken to fill gas different types of vehicles 


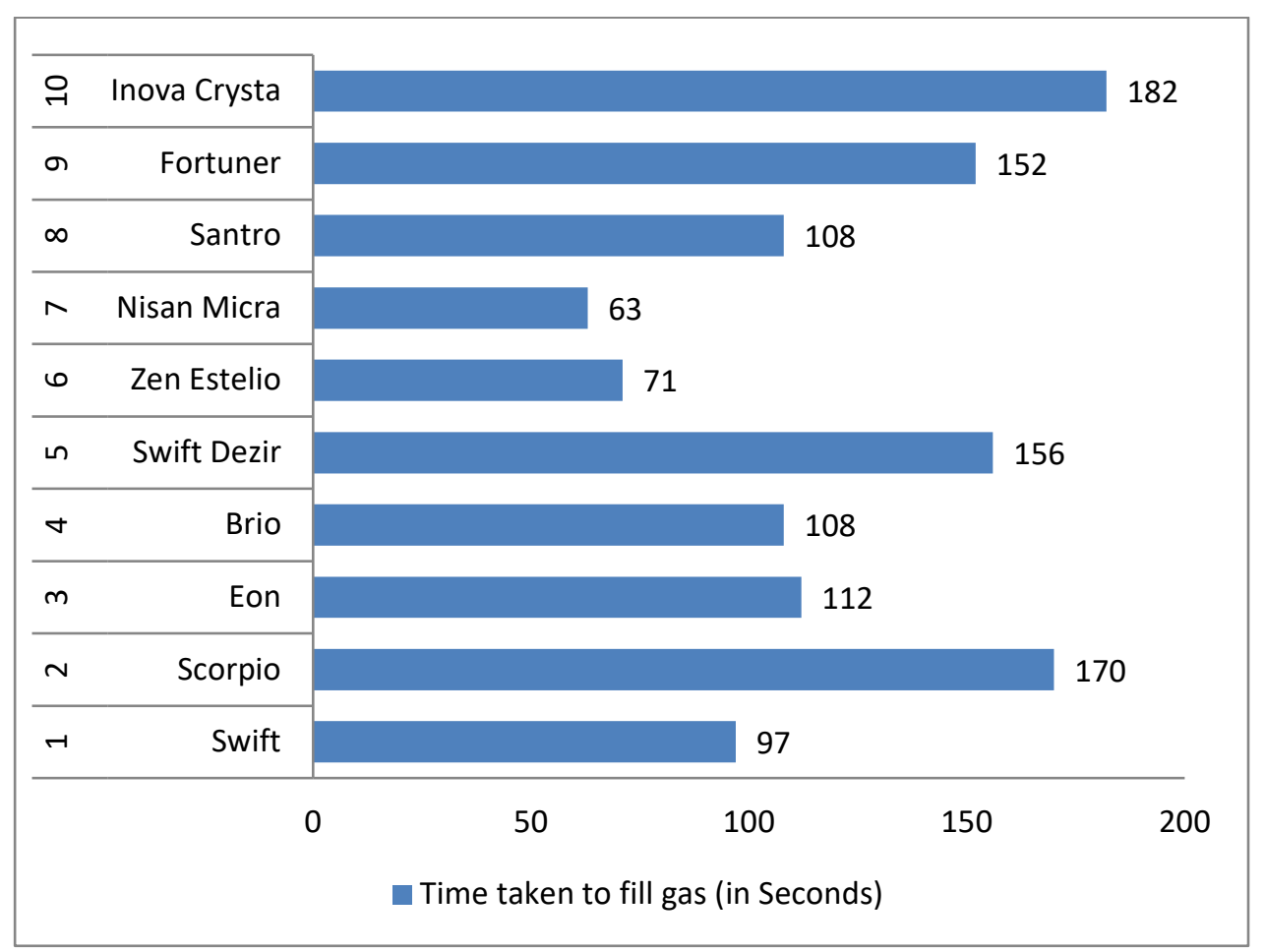

Graph 2: Time(in sec) taken to fill gas in different types of vehicles

\begin{tabular}{|l|l|l|l|}
\hline S.No & $\begin{array}{l}\text { Vehicle } \\
\text { Type }\end{array}$ & $\begin{array}{l}\text { Time taken } \\
\text { to fill gas } \\
\text { manually (in } \\
\text { Seconds) }\end{array}$ & $\begin{array}{l}\text { Time taken to fill gas by voice enabled system } \\
\text { (in Seconds) }\end{array}$ \\
\hline 1 & Swift & 97 & 85 \\
\hline 2 & Scorpio & 170 & 135 \\
\hline 3 & Eon & 112 & 100 \\
\hline 4 & Brio & 108 & 97 \\
\hline 5 & Swift Dezir & 156 & 140 \\
\hline 6 & Zen Estelio & 71 & 59 \\
\hline 7 & Nisan Micra & 63 & 51 \\
\hline 8 & Santro & 108 & 96 \\
\hline 9 & Fortuner & 152 & 132 \\
\hline 10 & Inova Crysta & 182 & 157 \\
\hline Average Time taken & 121.9 & 105.2 \\
\hline
\end{tabular}


As per the table and graphical analysis, the average time taken by 10 vehicle is $121.9 \mathrm{sec}$. The proposed system is help to reduce average timetaken by each ten vehicle by $16.7 \mathrm{secs}$.

IOT connectivity is rapidly changing the entire oil and gas industry, and the retail pump is no exception.

\section{Advantages and Disadvantages}

If a small microphone with a voice recognising chip imbedded into the system then every time when the car owner demands a new pressure to his/her car the worker simply presses the button and speak the no. The proposed system saves some number of seconds as earlier the worker needs to go to the machine and change the number.

The product will be cost efficient if it is easy to implement. The training of employees will be simple too as voice recognition tools like google assistant understands both English and Hindi. Every product's technology has their own merits and demerits. Some of them that we came across are mentioned below:

\section{Merits-}

- Saves the energy of the worker.

- More number of vehicles are entertained in less time.

- People prefer to visit a place where their time is saved. This results to increase the profits both directly and indirectly.

\section{Demerits-}

- $\quad$ Electronic devices break down easily.

- It depends upon the worker how clearly, he speaks, the clearer he is the more the faster the result will reflect.

- Need to have a technical person nearby so that if any problem occurs it could be resolved quickly.

\section{Conclusion and Future Scope}

This paper helps us to understand the use of a system that is integrated with IOT and AI, "AIR PUMPS" and their role in the development of smart cities.

Also, it explains the concept of how to develop such technology by providing a brief architecture of the whole system based on thorough research and surveys.

According to the Literature currently there are 60,000 petrol pumps in India. Among these, the different petrol pumps are divided into:

1) Indian Oil (IOCL) - 26,849

2) Bharat Petroleum (BPCL) - 14,675

3) Hindustan Petroleum (HP) - 14,161 
IOCL comprises of more petrol pumps than compared to both Canada and UK. If someone can save approximately 5 to $7 \mathrm{sec}$ on one vehicle, imagine how much time can be saved. Also, the paper gives a brief idea to someone about what IOT is.

Therefore, from the paper it becomes easier to understand the general architecture that is required to implement such technology and the uses of this technology along with its various merits and demerits.

\section{References}

1. M. Dohler, I. Vilajosana, X. Vilajosana, J. Llosa,"Smart Cities: An action plan", Proc. Barcelona Smart Cities Congress, " pp. 1-6, (Dec. 2011)

2. Cardone, G., Corradi, A., Foschini, L., "Convergence of MANET and WSN in IoT urban scenarios"Bellavista, ,IEEE Sens. J., vol. 13, no. 10,(Oct. 2013): pp.3558-3567

3. [fig.1] https://justcreative.com/2018/11/19/internet-of-things-explained/

4. L. Atzori, A. Iera, G. Morabito , "The internet of things: A survey",Computer Networks Elsevier B.V., vol. 54, no. 15, (2010) : pp. 2787-2805

5. [fig.2] http://indailytimes.com/wp-content/uploads/2019/03/Voice-RecognitionSystem-Market.png

6. Mohamned, Z., K., A., Ahmed, E., S., A.,"Internet of Things Applications, Challenges and Related Future Technologies", World Scientific News 67(2) (January2017) : pp.126-148

7. Prabhakar, O.,P., Sahu,N., K.,"Performance Improvement of Human Voice Recognition System using Gaussian Mixture Model International Journal of Advanced Research in Computer and Communication Engineering", International Journal of Advanced Research in Computer and

8. Communication EngineeringVol. 3, Issue 1, (January 2014): pp. 5257-5261, IJARCCE

9. Siegel, J., Kumar, S., Sarma, S., “The Future Internet of Things: Secure, Efficient, and Model-Based.” IEEE Internet of Things Journal 5, 4 (August 2018): 2386-2398 2018 IEEE

10. "Internet of Things for Smart Cities IEEE Internet of Things Journal", Zanella,A.,Bui, N., Castellani, A., ,Vangelista, L., ZorziM. , IEEE INTERNET OF THINGS JOURNAL ,Vol. 1 , No.1 , Feb. 2014 , page - 22-32 
11. Nandimath , J. N., Alekar V., Joshi, S., BhiteS.,Chaudhari ,P.,"IOT based fuel monitoring for future vehicles",International Research Journal of Engineering and TechnologyVolume: 04 Issue: 02 (Feb-2017)pp : 1361-1363

12. Sharma, K., Prasad, S., V., A., V. and Prasad, T., V., 2012, Hindi Speech Actuated Computer Interface for Web Search International Journal of Advanced Computer Science and Applications, Vol. 3, No.10, pp. 146-152.

13. Sharma, K., Suryakanthi, T., Smart system: IoT for university, 2015International Conference on Green Computing and Internet of Things (ICGCIoT), pp.1586-1593

14. Sharma, K., Suryakanthi, 2012 T. and Prasad, T., Exploration of speech enabled system for English, Proc. of the Int. Conf. on Sys. Modeling and Advancement in Research Trends (SMART), Teerthankar Mahaveer Univ., Moradabad, UP, India

15. Sharma, K. and Prasad, T., 2009, Swar The Voice Operated PC, Proc. of Nat. Conf. on Soft Computing and AI, NCSCAI 2009, Lingaya's Univ., Faridabad, Haryana, India

16. Sharma, K., Prasad, S., V., A., V. and Prasad, T., V., 2013 Hindi speech enabled windows application using Microsoft Sapi, International Journal of Computer Engineering \&Technology (IJCET), Volume4, Issue 2, pp.425-436

17. Sharma., K., 2017, Web Recognition of Spoken Hindi, Indian Journal of Science and Technology, Vol. 10, Issue. 35. 